\title{
Improving on effective antiretroviral therapy: how good will a cure have to be?
}

\author{
Kenneth A Freedberg, ${ }^{1,2}$ Paul E Sax ${ }^{3}$
}

\section{INTRODUCTION}

Over the past two decades we have seen dramatic improvements in the efficacy, safety and availibity of antiretroviral therapy (ART). In the USA and Europe, life expectancy in people living with HIV disease approaches that of the HIV-uninfected. ${ }^{1}$ Even in regions hardest hit by the HIV epidemic, effective HIV therapy has reversed more than a decade of HIV-related decreased survival.

Despite these advances in ART, motivations to pursue HIV cure remain strong due to the toxicity, adherence challenges, cost and access to care issues associated with HIV therapy, as well as the persistant stigma associated with having HIV infection. Further and renewed motivation comes from a single case of HIV cure after stem cell transplantation for acute leukaemia.

Given the tremendous improvements in ART, it is important to assess how effective and safe an HIV cure would need to be in order to be a viable option compared to ART. We argue that this should be done prior to the availability of a cure to provide realistic goals for researchers and policy makers.

\section{THE VALUE OF MATHEMATICAL AND COST-EFFECTIVENESS MODELS}

One methodology that has been increasingly popular over the past decade is the use of mathematical simulation modelling to assess the clinical impact, costeffectiveness and clinical role of different treatment strategies in HIV disease, as well as in medicine broadly. ${ }^{2}$ Such models provide a framework and approach for using the best available data at any point

\footnotetext{
${ }^{1}$ Medical Practice Evaluation Center and Divisions of General Internal Medicine and Infectious Diseases, Massachusetts General Hospital and Harvard Medical School, Boston, Massachusetts, USA; ${ }^{2}$ Department of Health Policy and Management, Harvard T.H. Chan School of Public Health, Boston, Massachusetts, USA; ${ }^{3}$ Division of Infectious Diseases, Brigham and Women's Hospital and Harvard Medical School, Boston, Massachusetts, USA

Correspondence to Dr Kenneth A Freedberg, MD, MSc, Medical Practice Evaluation Center, Massachusetts General Hospital, 50 Staniford St, Suite 901, Boston, MA, 02114, USA; KFREEDBERG@mgh.harvard.edu
}

in time, and assessing the potential impact of emerging innovations. Further, unlike individual trials focused on a single endpoint, these models can integrate multiple data sources to project beyond the timeline or outcomes of individual studies and project long-term outcomes in many domains, including virologic, immunologic, clinical and cost. ${ }^{3}$

\section{MODELLING UNCERTAINTY AND 'WHAT IF' ANALYSES}

Mathematical models have particular value in their ability to assess uncertainty in clinical care. Examples include parameters determined in clinical trials or cohort studies (such as the 95\% CIs) or the broader uncertainty over parameters that have not or cannot readily be measured in a trial, such as stigma. Another role of mathematical models is to estimate changes in care that may arise in the future; this is clearly of relevance for HIV cure research. Where many aspects of a potential intervention are uncertain, as is the case with the future of cure strategies, one can use a model to do a 'what if' analysis. What if a cure had an efficacy of $80 \%$ or $95 \%$ ? What if the severe toxicity rate was $0.1 \%$ or $10 \%$ ? What if the cost was $\$ 5000$ or $\$ 50000$ or $\$ 500000$ ? By varying multiple parameters, individually or in combination, this type of modelling can inform the ranges around which new therapeutic, or diagnostic, approaches could have a major clinical impact-especially compared with current therapy. Importantly, both efficacy and costs can be estimated. ${ }^{4}$

\section{UNDERSTANDING VALUE IN HEALTH: COST ANALYSIS AND COST-EFFECTIVENESS ANALYSIS}

Limited resources for health, in the context of increasingly effective interventions for multiple acute as well as chronic diseases, have meant that the demand for healthcare interventions outstrips the supply of available resources. This creates intense pressure to understand the efficacy of new interventions, as well as the cost and cost-effectiveness of these strategies. Cost analysis examines one outcome, cost, and is used generally for budgeting and understanding how introducing a new diagnostic test or therapy will affect healthcare budgets and costs. Cost-effectiveness analysis goes further by attempting to measure 'value for money' through an assessment of the costs of an intervention, as well as the clinical benefits, usually measured in changes in life expectancy or quality-adjusted life expectancy. ${ }^{5}$ The outcome of these analyses is the incremental cost-effectiveness ratio (ICER), which is denominated in dollars/ year of life saved (\$/YLS), dollars/ quality-adjusted life year (\$/QALY) saved or dollars/disability-adjusted life year (\$/DALY) saved. The lower the ratio, the more cost-effective the intervention. This is effectively a measure of value for money-how much are we spending to improve outcomes-compared with other possible interventions.

\section{DEFINING COST-EFFECTIVENESS}

How can one determine if something is 'cost-effective'? Different countries spend vastly different resources on health, so what might be considered cost-effective in one country might not be in another. While there is no consensus on what is 'cost-effective' in the USA, a widely cited threshold is that strategies with an ICER $<\$ 100000 /$ QALY are considered costeffective in the USA. ${ }^{6}$ The WHO historically has said that cost-effectiveness is likely related to the annual per person gross domestic product (GDP) in a country. An intervention might be considered 'cost-effective' if its ICER were below three times the per capita GDP; it might be considered 'very cost-effective' if its ICER were below one times the GDP. More recently, it has been suggested that most resource-limited countries cannot afford to add to their healthcare portfolio interventions with ICERs this high, and that 'cost-effective' strategies might be those with ICERs below half the GDP or even less. ${ }^{8}$ Regardless of the exact definition of what a country might be willing to pay for healthcare, determining an ICER allows one to rank the relative value of different interventions of interest. ${ }^{2}$

\section{SETTING-SPECIFIC CARE}

Current ART, and HIV care more broadly, differs substantially in different countries. In the USA, Europe and Australia, guidelines for care include ART at the time infection is diagnosed, with genotype testing before care and at the time of virologic failure, as well as virologic monitoring and access to over 30 licensed medications. While the WHO in late 2015 recommended ART at the time of HIV 
diagnosis, based on the results of the Temprano and START trials, in many resource-limited settings, criteria for ART initiation remains at a CD4 threshold of $<350$ or $<500$ cells/ $\mu \mathrm{L} .{ }^{3} 910$ Many countries do not have routine virologic monitoring or genotype tests, and integrase inhibitor-based therapy is not recommended for first-line therapy, reserved only for extraordinary cases or is not available at all. ${ }^{10} 11$ Thus, the potential use, impact, cost and cost-effectiveness of any cure strategy should be considered in the context of currently available therapy. Where therapy is widely available, highly effective and safe, cure strategies would offer less incremental value than in settings where such therapy is not as available.

\section{A 'WHAT IF' ANALYSIS OF HIV CURE IN THE USA \\ Objective and approach}

We set out to use mathematical modelling to understand what characteristics an HIV cure strategy would have to have to improve on currently available ART in the USA. $^{4}{ }^{12}$ For our analysis, we used the Cost-effectiveness of Preventing AIDS Complications (CEPAC) model, a validated and widely published microsimulation of the natural history and treatment of HIV disease. ${ }^{31314}$ The model includes data from multiple cohort studies, clinical trials and economic analyses and it has been used to assess a wide variety of treatments, diagnostic tests and testing strategies for HIV disease in the USA as well as in many other countries. The model incorporates the most currently available data and is updated regularly.

\section{Strategies}

We incorporated into our analysis three approaches studied in HIV cure research, as detailed in Sax et al. ${ }^{4}$ These include gene therapy, ${ }^{15}$ the 'kick and kill' strategies, which are similar to chemotherapy for cancer $^{16}$ and stem cell transplant. ${ }^{17}$ We considered a gene therapy strategy as potentially having lower efficacy but less toxicity, a chemotherapy strategy having moderate efficacy and toxicity and a bone marrow transplant strategy as having the highest likely efficacy as well as toxicity. Since none of these strategies are available currently for HIV cure, in each case, we varied parameters across a wide range in sensitivity analyses.

\section{Assumptions going into the model}

We used several assumptions meant to reflect the current state of cure research. First, we assumed that patients eligible for cure therapy had already been on 1 year of suppressive ART. Second, if a cure strategy failed, either initially or with later relapse, we assumed that ART would be resumed, with no reduction in ART efficacy. Third, we did not include the possibility of reinfection in those cured of HIV. Fourth, we did not adjust for the impact of a cure strategy on the likelihood of individuals developing chronic 'non-AIDS' specific complications, such as heart disease and cancer. Finally, it is possible that cure could decrease the potential of people living with HIV to pass on HIV, even though we are comparing cure with ART in those already suppressed. This omitted factor would make a cure more attractive relative to ART.

\section{Clinical and cost inputs}

Since there are no proven effective cure strategies, most of the inputs were hypothetical; in terms of toxicity and relapse, they were based on similar data from other interventions with gene therapy, chemotherapy or bone marrow transplant.

We used an initial efficacy of 10\%, 20\% and $70 \%$ for gene therapy, chemotherapy and bone marrow transplant, respectively. Fatal toxicity ranged from $0.1 \%$ to $5.0 \%$, with non-fatal toxicity ranging from $1 \%$ to $55 \%$. Relapse rates after 'successful' cure ranged from $0 \%$ to $0.5 \% /$ month.

Cost inputs were also based, where possible, on data from similar types of therapies. Cost for gene therapy was $\$ 101000$, for chemotherapy $\$ 12400 /$ month for 24 months, and for bone marrow transplant $\$ 123$ 900, with additional costs of $\$ 1000 /$ month for immunosuppressive medications. In the model, the cost of firstline ARTwas \$24 000/year on average.

\section{Main results of the analysis}

We found that, based on the assumptions in the model, gene therapy would offer a modest increase in life expectancy compared with ART (from 16.4 to 16.6 discounted QALYs), while it would increase lifetime costs from $\$ 591000$ to $\$ 659,000$ for an ICER of $\$ 331000 /$ QALY. This is well above the commonly discussed willingness-to-pay thresholds in the USA of $\$ 100000 /$ QALY, suggesting that, under the assumptions in the model, a gene therapy approach would not be costeffective. For the chemotherapy and bone marrow transplant approaches, the results were even less attractive. Because of the toxicity of both chemotherapy and bone marrow transplant approaches, particularly the initial toxicity, they were associated with the same or worse life expectancy as continued ART and had substantially higher costs.
How good would a cure need to be?

By varying parameters in the model individually and in combination we could identify the 'targets' at which each of these strategies might improve life expectancy and be cost-effective compared with continuing suppressive ART. For gene therapy, if the efficacy were $22 \%$, the ICER dropped below \$100 000/QALY; with an efficacy of $34 \%$, it became costsaving compared with ART. The efficacy of chemotherapy had to be $88 \%$ to have an ICER $<\$ 100000 /$ QALY and it never became cost-saving. Bone marrow transplant had an ICER $<\$ 100000 /$ QALY at an efficacy of $79 \%$, and became cost-saving with an efficacy of $80 \%$. For each of these strategies, if there were no risk of relapse - that is, the cure was completely durable -then the efficacy needed to achieve cost-effectiveness or cost-saving thresholds was lower. Finally, for all of the strategies, if an effective cure improved patients' quality of life compared with their quality of life on ART, then each of the strategies became even more attractive. This depended in large part on the baseline quality of life for patients receiving ART. If that quality of life was low (eg, based on the psychological stressors and stigma associated with having HIV), then the potential benefit of cure was higher.

\section{Why cure strategies are unique in HIV modelling analyses}

We and other investigators have examined multiple HIV interventions, including HIV testing, first-line, second-line and later ART, as well as diagnostic tests including viral load and resistance genotype testing. ${ }^{13}{ }^{18-21}$ For virtually all interventions in HIV disease-treatments or diagnostic tests-the intervention improves survival at added cost, allowing one to determine whether it has an attractive cost-effectiveness ratio. It is rare for a strategy to actually be cost-saving, including even 'win-win' interventions such as the use of early ART for treatment as prevention. The primary reason these are not cost-saving is because each of these treatment strategies to date involves continuing therapy lifelong.

Our cure analysis yielded qualitatively different results. We found that across a wide range of assumptions, strategies were unlikely to be cost-effective compared with ART. In a much narrower range, there were estimates at which cure might be cost-effective, that is, increasing life expectancy as well as cost, with an attractive ICER. But as we continued to assess each of these parameters, whether efficacy, 
toxicity, relapse rate or cost, the cure strategies then uniformly became cost-saving. Thus, there is only a narrow parameter range in which cure would be costeffective rather than either cost-saving or not cost-effective. With high efficacy, cure could indeed be cost-saving. The primary explanation for this finding is that an effective cure would eliminate the need for lifelong ART.

\section{Limitations}

This type of analysis is most importantly limited by the lack of real data on cure strategies. For that reason, we varied each estimate across a wide range to determine its impact on the results. Our assumption that patients undergoing a cure strategy already be virally suppressed-that is, successfully treated-for a year could create a bias against a cure, since those patients are likely to continue to do well on ART. They are, however, the patients thought most likely to be able to be cured at present. ${ }^{22}$ As challenging as HIV eradication would be in a patient with virologic suppression, it is currently scientifically implausible to imagine doing so in someone with ongoing high-level viral replication. We assumed that if a cure failed, patients could resume ART. If ART efficacy were reduced, either due to resistance or other reasons, cure would look worse. If we incorporated the possibility of reinfection after cure, then cure would be even less attractive. In terms of 'non-AIDS' complications, it is possible that a cure could decrease these by changing the factors that are increasing these complications, or increase them, as has been seen with chemotherapy for other diseases. We also do not consider the potential increased likelihood of transmission from those on ART, if they have virologic failure, compared with those cured. Finally, this analysis is based on data from the USA, including both clinical and cost data. The results may differ substantially in other developed as well as resourcelimited settings. Given that the cost of ART is much lower in resource-limited settings than in the USA, it is likely, given increased access to ART via PEPFAR, the Global Fund and country-specific programmes, that a cure strategy would have to have correspondingly lower cost to be a viable alternative to effective ART.

\section{CONCLUSIONS}

Despite the success of current ART, substantial resources are being invested in researching HIV cure strategies. Although the efficacy, toxicity, relapse and cost parameters around HIV cure strategies are not yet known, it is possible with the use of mathematical modelling to determine the set of targets for these parameters under which HIV cure would be a reasonable alternative to ART. If novel approaches can achieve some of these challenging targets, cure would turn out to be costsaving compared with ART, as a lifelong treatment with ART can then be avoided.

Acknowledgements The authors thank Amy Zheng for her assistance with the manuscript.

Funding Supported in part by R01 Al42006, R01 Al114617, R56 Al114617 and the Harvard University Center for AIDS Research (NIH P30 AI060354), all from the National Institute of Allergy and Infectious Diseases. The content is solely the responsibility of the authors and does not necessarily represent the official views of the National Institutes of Health.

\section{Competing interests None.}

Provenance and peer review Commissioned; externally peer reviewed.

\section{6 \\ OPEN ACCESS}

Open Access This is an Open Access article distributed in accordance with the Creative Commons Attribution Non Commercial (CC BY-NC 4.0) license, which permits others to distribute, remix, adapt, build upon this work non-commercially, and license their derivative works on different terms, provided the original work is properly cited and the use is noncommercial. See: http://creativecommons.org/licenses/ by-nc/4.0/

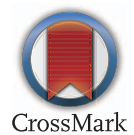

To cite Freedberg KA, Sax PE. J Med Ethics 2017:43:71-73.

Received 26 August 2016

Revised 24 October 2016

Accepted 3 November 2016

Published Online First 5 December 2016

J Med Ethics 2017:43:71-73.

doi:10.1136/medethics-2016-103907

\section{REFERENCES}

1 Rodger AJ, Lodwick R, Schechter M, et al. Mortality in well controlled HIV in the continuous antiretroviral therapy arms of the SMART and ESPRIT trials compared with the general population. AIDS 2013;27:973-9.

2 Drummond MF, Sculpher MJ, Torrance GW, et al. Methods for the economic evaluation of health care programmes. 3rd edn. Oxford: Oxford University Press, 2005.

3 Walensky RP, Ross EL, Kumarasamy N, et al. Cost-effectiveness of HIV treatment as prevention in serodiscordant couples. N Engl J Med 2013:369:1715-25.

4 Sax PE, Sypek A, Berkowitz BK, et al. HIV cure strategies: how good must they be to improve on current antiretroviral therapy? PLOS ONE 2014;9:e113031.

5 Ubel PA, Hirth RA, Chernew ME, et al. What is the price of life and why doesn't it increase at the rate of inflation? Arch Intern Med 2003;163:1637-41.

6 Neumann PJ, Cohen JT, Weinstein MC. Updating cost-effectiveness - the curious resilience of the
\$50,000-per-QALY threshold. N Engl J Med 2014:371:796-7.

7 World Health Organization. CHOosing interventions that are cost effective (WHO-CHOICE): cost-effectiveness thresholds. http://www.who.int/ choice/costs/CER_levels/en/ (accessed 15 Jul 2016).

8 Revill $P$, Walker $\bar{S}$, Madan J, et al. Using cost-effectiveness thresholds to determine value for money in low- and middle-income country healthcare systems: are current international norms fit for purpose? CHE Research Paper 98. 2014. http://www. idsihealth.org/wp-content/uploads/2015/01/ Cost-Effectiveness-Thresholds Value_Low-MiddleIncome-Countries_York.pdf (accessed 15 Jul 2016).

9 World Health Organization. Guideline on when to start antiretroviral therapy and on pre-exposure prophylaxis for HIV. 2015. http://apps.who.int/iris/ bitstream/10665/186275/1/9789241509565_eng. pdf (accessed 15 Jul 2016).

10 South Africa Department of Health. National consolidated guidelines for the prevention of mother-to-child transmission of HIV (PMTCT) and the management of HIV in children, adolescents and adults. 2015. http:/l www.sahivsoc.org/upload/documents/ART\%20Guidelines \%2015052015.pdf (accessed 15 Jul 2016).

11 National AIDS Control Organisation. National guidelines on second-line and alternative first-line ART for adults and adolescents. 2013. http://www. naco.gov.in/upload/Policies\%20\&\%20Guidelines/ National\%20Guidelines\%20on\%20Second-line\% 20and\%20Alternative \%20First-line \%20ART\%20For $\% 20$ Adults $\% 20$ and $\% 20$ Adolescents $\% 20$ May $\%$ 202013.pdf (accessed 15 Jul 2016).

12 Panel on Antiretroviral Guidelines for Adults and Adolescents, Department of Health and Human Services (DHHS). Guidelines for the use of antiretroviral agents in HIV-1-infected adults and adolescents. 2016. http://aidsinfo.nih.gov/ contentfiles/lvguidelines/adultandadolescentgl.pdf (accessed 15 July 2016)

13 Freedberg KA, Losina E, Weinstein MC, et al. The cost effectiveness of combination antiretroviral therapy for HIV disease. N Engl J Med 2001;344:824-31.

14 Paltiel $A D$, Weinstein $M C$, Kimmel $A D$, et al. Expanded screening for HIV in the United States-an analysis of cost-effectiveness. $N$ Engl J Med 2005;352:586-95.

15 Tebas $\mathrm{P}$, Stein D, Tang WW, et al. Gene editing of CCR5 in autologous CD4 T cells of persons infected with HIV. N Engl J Med 2014;370:901-10.

16 Archin NM, Liberty AL, Kashuba AD, et al. Administration of vorinostat disrupts HIV-1 latency in patients on antiretroviral therapy. Nature 2012;487:482-5.

17 Allers K, Hütter G, Hofmann J, et al. Evidence for the cure of HIV infection by CCR5Delta32/Delta32 stem cell transplantation. Blood 2011;117:2791-9.

18 Walensky RP, Paltiel AD. Rapid HIV testing at home: does it solve a problem or create one? Ann Intern Med 2006;145:459-62.

19 Sax PE, Islam R, Walensky RP, et al. Should resistance testing be performed for treatment-naive HIV-infected patients? A cost-effectiveness analysis Clin Infect Dis 2005;41:1316-23.

20 Phillips A, Cambiano V, Nakagawa F, et al. Cost-effectiveness of HIV drug resistance testing to inform switching to second line antiretroviral therapy in low income settings. PLOS ONE 2014;9:e109148.

21 Hutchinson AB, Farnham PG, Sansom SL, et al. Cost-effectiveness of frequent HIV testing of high-risk populations in the United States. J Acquir Immune Defic Syndr 2016;71:323-30.

22 Mellors J, McMahon D. Evaluating the safety and efficacy of single-doseromidepsin in combination with antiretroviral therapy in HIV-infected adult with suppressed viral load. NCT01933594. http:/ clinicaltrials.gov/ct2/show/NCT01933594? term=romidepsin+hiv\&rank=1 (accessed $15 \mathrm{Jul}$ 2016). 